Dossiê: Vida na rua

\title{
Perigosos ou úteis? \\ Os moradores de rua e a produção do espaço urbano em Belo Horizonte e Bogotá
}

\author{
Dangerous or useful? \\ Homeless people and urban space production \\ in Belo Horizonte and Bogotá \\ Peligrosos o útiles? \\ Los habitantes de calle y la produción del espacio urbano \\ en Belo Hozonte y Bogatá
}

Karine Gonçalves Carneiro ${ }^{1}$

\begin{abstract}
Resumo: Neste artigo buscaremos analisar os mecanismos e estratégias de poderes/ saberes que interferem, no âmbito do planejamento urbano e da produção do espaço, sobre as pessoas moradoras de rua em Belo Horizonte e Bogotá a partir de investigações que ocorreram durante os anos 2014 e 2015. Para tal, procuraremos compreender como o planejamento urbano neoliberal tem transformado espaços públicos - locais de estruturação, parcial ou total, da vida dos moradores de rua - em commodity através de estratégias de privatização. Os procedimentos teórico-metodológicos utilizados foram baseados na etnografia e na genealogia foucaultiana - que possibilitaram tanto acompanhar a construção de uma razão neoliberal através dos tempos quanto a produção de dispositivos, no âmbito da política urbana, com o intuito de controlar corpos nas dimensões do indivíduo e da população. Nessa perspectiva, conduziremos um olhar para o espaço urbano a partir de corpos e pessoas compreendidos não como problemas, mas como parte de conflitos, pertencimentos, estratégias, formas de sujeição e exclusões com o intuito de pensar a produção do espaço de forma crítica.
\end{abstract}

Palavras-chave: Moradores de rua; Analítica do poder/saber; Produção do espaço; Belo Horizonte; Bogotá.

Abstract: In this article, we will analyze the mechanisms and strategies of power/ knowledge that interfere, in the scope of urban planning and space production, on the life of homeless people in Belo Horizonte and Bogota, based on investigations that occurred during the years 2014 and 2015. To this purpose, we will try to understand how neoliberal urban planning has transformed public spaces - places of partial or total structuring of the life of the homeless - in commodity through strategies of privatization. The theoretical-methodological procedures used were based on Foucault's ethnography

\footnotetext{
${ }^{1}$ Universidade Federal de Ouro Preto (Ufop, Ouro Preto, MG, Brasil). autora.dados_biográficos
} 
and genealogy, which enabled both the construction of a neoliberal reason through time and the production of devices within urban policy to control bodies in two dimensions: individual and populational. In this perspective, we will take a look at the urban space from bodies and people understood not as problems, but as part of conflicts, belongings, strategies, forms of subjection and exclusions with the intention of thinking about the production of space in a critical way.

Keywords: Homeless; Power/knowledge analytics; Space production; Belo Horizonte; Bogotá.

Resumen: En este artículo, buscaremos analizar los mecanismos y estrategias de poderes/saberes que interfieren en el ámbito de la planificación urbana y de la producción del espacio sobre las personas habitantes de calle en Belo Horizonte y Bogotá a partir de investigaciones que ocurrieron durante los años 2014-2015. Procuraremos comprender cómo la planificación urbana neoliberal ha transformado espacios públicos - locales de estructuración, parcial o total, de la vida de los habitantes de calle - en commodity a través de estrategias de privatización. Los procedimientos teórico-metodológicos utilizados se basaron en la etnografía y en la genealogía foucaultiana - que permitieron tanto acompañar la construcción de una razón neoliberal a través de los tiempos como la producción de dispositivos, en el ámbito de la política urbana, con el propósito de controlar cuerpos en las dimensiones individual y poblacional. En esa perspectiva, conduciremos una mirada al espacio urbano a partir de cuerpos y personas comprendidas no como problemas, sino como parte de conflictos, pertenencias, estrategias, formas de sujeción y exclusiones con el intuito de pensar la producción del espacio de forma crítica.

Palavras clave: Habitantes de calle; Analítica del poder/saber; Producción del espacio; Belo Horizonte; Bogotá.

\section{Introdução}

O presente artigo é fruto de uma tese de doutorado que teve como objetivo identificar e analisar, por meio de uma abordagem genealógica, os mecanismos, estratégias e táticas de poderes/saberes que têm interferido ou atuado - no âmbito das intervenções sobre o urbano em função do planejamento público - sobre os modos de vida dos moradores de rua ${ }^{1}$ nas cidades de Belo Horizonte e de Bogotá, no tocante às suas relações com os espaços públicos. No caso específico deste texto, evidenciaremos as formas como tais relações de poderes/saberes incidiram sobre a dimensão do corpo individual - anátomopolítica - e do corpo populacional - biopolítica - dos moradores de rua tendo como base a construção de uma razão neoliberal. Em outras palavras, a partir da analítica do poder/saber foucaultiana investigaremos como o poder disciplinar

\footnotetext{
${ }^{1}$ A população heterogênea que tem na rua a base de sua existência, quando geralmente identificada pelo senso comum, recebe denominações que ressaltam supostos perfis que variam não apenas historicamente como também a partir do sujeito da fala. Para efeito deste trabalho será utilizado o termo "moradores de rua". Tal posicionamento vem em função da forma majoritária pela qual se autodenominaram - em ambas as cidades - ao longo da investigação.
} 
e o biopoder, no âmbito dos processos de produção do espaço da cidade, têm produzido formas de assujeitamento. ${ }^{2}$

Para levar a cabo tal empreitada, primeiramente, esclareceremos como o referencial teórico foi delineado para, em seguida, ressaltar, no escopo das atividades metodológicas, a forma como o método genealógico foucaultiano tornou-se central no trabalho. No momento seguinte, lançaremos o olhar sobre as cidades de Belo Horizonte e Bogotá tendo em vista os jogos de poderes e saberes que, através de mecanismos, estratégias e táticas, têm permeado a vida dos que moram nas ruas vis a vis os modos como as políticas públicas, no âmbito do urbano, têm interferido na produção dos espaços citadinos. $\mathrm{Na}$ atualidade, esta dinâmica tem sido levada a cabo por processos mercantilistas e privatistas, frutos de uma arte de governar neoliberal, nos quais a terra urbana vem sendo transformada em commodity a partir da formatação de novos desenhos de administração. Tais desenhos não mais atuam por meio de modelos gerenciais, mas sim de um modelo de empreendedorismo que percola desde um nível mais amplo - ou global - até o nível local, inaugurando uma nova forma de gestão dos espaços conhecida como "empreendedorismo urbano". Finalmente, mostraremos os impactos e desdobramentos desses processos no que tange à vida das pessoas moradoras de rua.

\section{Poder disciplinar e biopoder: uma analítica do espaço "com" e "através de" Foucault}

No que concerne às discussões teórico-conceituais, a pesquisa realizada centrou-se na analítica de poderes/saberes desenvolvida por Michel Foucault. A presença de Foucault justifica-se pela forma como o autor compreende o espaço com base nas relações de poderes/saberes que o atravessam. Essa possibilidade de aproximação do cotidiano e do espaço, a partir de Foucault, ocorre, conforme indica Prigge (2008), devido às intervenções subversivas do autor nas práticas discursivas dominantes, com o objetivo de restaurar o poder prático aos saberes sujeitados. Nesse sentido, a noção de espaço se desdobra para regiões que vão mais além de definições cartesianas em termos matemáticos ou das definições unicamente científicas e hegemônicas.

\footnotetext{
${ }^{2}$ É importante ressaltar que do trabalho mais abrangente relacionado à tese foram extraídas argumentações e perspectivas relacionadas à produção do espaço citadino face às estratégias e táticas de poder/saber como mecanismos que incidem sobre a população de rua no âmbito do planejamento urbano. Tal fato implica que, muito embora a pesquisa doutoral tenha também se debruçado, cuidadosamente, sobre o cotidiano e o dia a dia das pessoas moradoras de rua - portadoras de histórias, memórias e discursividades -, optamos por dar profundidade, no presente texto, à ênfase acima mencionada em função dos limites inerentes a um artigo e para evitar simplificações e/ou superficialidades.
} 
É sabido, entretanto, que Foucault não colocou as questões sobre o espaço como foco central de sua análise. Todavia, ele o abordou de maneira reincidente e complexa. Como ressalta Stuart Elden (2001, p. 3), "a norma para Foucault é usar o espaço não meramente como uma outra área a ser analisada, mas como uma parte central de suas aproximações". Foi este, por exemplo, o caso dos hospícios, prisões e casas de internamento em A história da loucura na idade clássica, publicado em 1961. Ali, Foucault (1978) mostrou como (re) configurações de poderes/saberes vão formatando espaços morais de exclusão - majoritariamente da pobreza - que segregam e retiram dos espaços das cidades aqueles corpos considerados não conformes ou anormais, em cada período histórico específico.

Da mesma maneira, em o Nascimento da clínica, de 1963, o autor pontuou como o hospital escola e a medicina clínica estiveram relacionados com alterações imbricadas no próprio corpo humano como espaço de ação de poderes e de estabelecimento de saberes a partir de uma nova racionalidade médica. Não é casual, portanto, que a primeira frase do prefácio desta obra seja: "Este livro trata do espaço, da linguagem e da morte; trata do olhar" (Foucault, 1977, p. VII). Trata, portanto, da "espacialização e da verbalização fundamentais do patológico" (Foucault, 1977, p. X); na localização da doença no espaço do corpo e do doente em espaços institucionalizados para seu conhecimento, escrutínio e análise.

Já Vigiar e Punir: nascimento da prisão, de 1975, é o livro mais explorado de Foucault (2009), no que concerne às questões espaciais, quando consideramos estudos na área da arquitetura e do urbanismo. ${ }^{3}$ As análises e descrições da cidade da peste, da cidade carcerária, do acampamento militar e das prisões - afora as análises das punições que ocorriam nas praças e ruas de séculos mais pregressos - permitiram chegar à exploração do modelo panóptico que evidencia os modos como o espaço e, principalmente, a cidade, é usado como um mecanismo de poder, de um poder, mais especificamente, disciplinar.

A analítica do poder/saber a partir de uma perspectiva espacial não se encerra nestas obras já apresentadas. "Esta genealogia da alma moderna e do policiamento dos espaços urbanos [...] não é perseguido simplesmente em Vigiar e Punir [...]. É também mais tarde desenvolvido na série História da sexualidade" (Elden, 2001, p. 150). Principalmente no primeiro livro, de 1976, História da sexualidade I - A vontade de saber, Foucault (1988) mostrou o modo como, entre os séculos 17 e 19, novas regras da decência se

\footnotetext{
${ }^{3}$ O que pode ser verificado em Cortés (2008), Santos (1988) e Nascimento (2008).
} 
instauraram nos discursos sobre o sexo e sobre uma reorientação dos desejos. Na transformação dos processos de diferenciações hierárquicas, o sangue azul dos nobres deu lugar à sexualidade burguesa sadia na qual o espaço foi também mecanismo regulador e de vigilância.

Mas talvez uma das contribuições mais importantes de História da sexualidade $I$, do ponto de vista das análises espaciais, seja a enunciação de uma outra forma de relação de poderes/saberes que recai não mais sobre o corpo individual, mas sobre o corpo da população. É o poder sobre o homemespécie, o poder sobre a vida, o biopoder que se exerce através de uma biopolítica, de uma tecnologia política da vida:

O homem ocidental aprende pouco a pouco o que é ser uma espécie viva num mundo vivo, ter um corpo, condições de existência, probabilidade de vida, saúde individual e coletiva, forças que podem se modificar, e um espaço em que se pode reparti-las de modo ótimo (Foucault, 1988, p. 155).

Esse espaço de distribuição é o espaço das cidades, que captura indivíduos e população. Nele, as pessoas passaram a ser localizadas a partir de domínios de valor e de utilidade, no qual vigilâncias infinitesimais - da disciplina e de controle -, os micropoderes, somaram-se a esquemas constantes de ordenações espaciais. Nesse sentido, os problemas atribuídos à população formatavam problemas relacionados ao espaço urbano e vice-versa. Foi deste modo que, em meados do século 19, sob o comando do estado, equipes médicas e higienistas passaram a vasculhar praças, ruas, bares, clubes, bordéis e prisões.

Os espaços citadinos são também constantemente abordados por Foucault nos cursos do Collège de France que ocorreram entre os anos de 1970 e 1982. Neles há o aprofundamento do pensamento sobre o poder disciplinar, o biopoder e a biopolítica. Da cidade medieval à moderna, são mostrados mecanismos que tinham como objetivo excluir os corpos não conformes; puni-los exemplarmente em espaços públicos; trancafiá-los e/ou localizá-los; e posicioná-los diante de estruturas hierárquicas de caráter espacial - fosse por meio do próprio desenho dos espaços, fosse através de limites ótimos de distribuição baseados na demografia e estatística, fosse no exercício conjunto destes dois mecanismos.

Nesse contexto, ressaltamos a forma como Foucault trata a noção dos dispositivos de segurança, tema do curso de 1977-1978, que deu origem ao volume Segurança, território, população. A importância em abordá-los reside no fato de que tais dispositivos passaram a atuar sobre o corpo populacional, de modo a criar médias de eventos que poderiam se considerados aceitáveis 
ou normais dentro dos espaços da cidade. Ou seja, à normatização anátomopolítica dos corpos - do poder disciplinar que recai sobre o indivíduo através de técnicas médicas, psicológicas e policiais que controla, vigia, aperfeiçoa e estabelece padrões de normalidade -, somaram-se mecanismos de normalização da vida - as curvas ótimas de mortalidade, criminalidade, nascimento etc. ${ }^{4}$ Trata-se:

de maximizar os elementos positivos, de poder circular da melhor maneira possível, e de minimizar, ao contrário, o que é risco e inconveniente, como o roubo, as doenças, sabendo que nunca serão suprimidos. [...] o que se vai procurar estruturar nesses planejamentos são os elementos que justificam por sua polifuncionalidade. $\mathrm{O}$ que é uma boa rua? É uma rua que vai haver, é claro, uma circulação dos chamados miasmas, logo das doenças, e vai ser necessário administrar a rua em função desse papel necessário, embora pouco desejável da rua. A rua vai ser também aquilo por meio do que se levam as mercadorias, vai ser também aquilo ao longo do que vai haver lojas. A rua vai ser também aquilo pelo que vão poder transitar os ladrões, eventualmente amotinados etc. (Foucault, 2008a, p. 26).

Passou-se, assim, do adestramento do corpo útil, do corpo dócil, à normalização da própria conduta da espécie, ao biopoder que atua sobre estratégias de uma biopolítica.

[...] regrar, manipular, incentivar e observar fenômenos como as taxas de natalidade e mortalidade, as condições sanitárias das grandes cidades, o fluxo das infecções e contaminações, a duração e as condições da vida, etc. Assim, o que se produz por meio da atuação específica do biopoder não é mais apenas o indivíduo dócil e útil, mas é a própria gestão calculada da vida do corpo social (Duarte, 2009, p. 6).

Com essas considerações sobre o poder disciplinar e o biopoder, a partir da analítica do poder/saber foucaultiana, buscamos evidenciar como o espaço é atravessado e gera atravessamentos pelos/aos indivíduos e pela/à população. Embora as situações e espaços descritos acima não falem ou digam respeito,

\footnotetext{
${ }^{4}$ Essa distinção de modos de atuação de poderes/saberes em épocas distintas não implica que cada um deles seja exclusivo de um período. Havia dispositivos de segurança já na idade média, assim como na atualidade estamos sujeitos a regimes de legalidade. Do mesmo modo, a disciplina perpassa todos os períodos elencados. A questão é a forma como certos rearranjos de seus mecanismos, táticas e estratégias dão origem a uma forma de tecnologia política que passa a atuar de modo mais ostensivo, em determinado tempo histórico, sobre o indivíduo e/ou população.
} 
especificamente, às pessoas que vivem nas ruas, as ações normalizadoras e normatizadoras - que advém desses poderes - desenham a tênue linha que cria e separa aqueles que são produzidos como normais daqueles que, por não se sujeitarem à disciplina ou ao controle, conformam indivíduos e/ou populações consideradas anormais. Dentre eles, estão as pessoas moradoras de rua.

\section{Etnografia e genealogia: afetos e encontros que se somam à história do presente}

No âmbito dos procedimentos metodológicos que cercaram este trabalho, antes de adentrar nas questões que dizem respeito à genealogia, é mister destacar um método que lhe foi complementar, a saber, a etnografia. Uma etnografia que, através da experiência de campo, foi aporte fundamental para a análise das relações de poderes/saberes e que se baseou nos encontros - ou occursus, 5 se consideramos a aula de Gilles Deleuze (2015) sobre ideia e afeto em Spinoza - e no "ser afetado" que tanto Deleuze quanto Jeanne FavretSaada (2005) - ao descrever seus estudos sobre feitiçaria no Bocage francês evidenciaram como instrumento de conhecimento. Uma etnografia que buscou reconhecer e reafirmar a existência de outros saberes: saberes locais, populares, ordinários, sujeitados. Saberes, no caso deste trabalho, cotidianamente (re) construídos pelos moradores de rua a partir dos enfrentamentos e lutas com outros sujeitos, com o espaço - que tanto os circundam como que se preenchem com sua presença - e entre eles mesmos. Foram esses saberes que, dentro de um quadro teórico-metodológico mais geral, buscamos encontrar e, pelo encontro, deixarmo-nos afetar.

Nesse sentido, tanto em Belo Horizonte quanto em Bogotá, as atividades de campo - que ocorreram durante os anos de 2014 e 2015 - contemplaram o mapeamento e a identificação das instituições públicas e grupos de assistência ${ }^{6}$

\footnotetext{
${ }_{5}$ A importância do encontro está ressaltada nesta passagem de Deleuze (1978): "Ora, um corpo deve ser definido pelo conjunto das relações que o compõe, ou, o que dá exatamente no mesmo, pelo seu poder de ser afetado. E enquanto vocês não souberem qual é o poder de ser afetado de um corpo, enquanto vocês o aprenderem assim, ao acaso dos encontros, vocês não estarão de posse da vida sábia, não estarão de posse da sabedoria" (Deleuze, 1978, s.p.).

${ }^{6}$ Em Bogotá podemos citar a Pastoral de Calle - sob a responsabilidade da Comunidad de las Hijas de la Caridad de San Vicente de Paúl, encarregada da direção do Centro Ambulatório Medalla Milagrosa, que oferta serviços e programas aos habitantes de calle; a Secretaría Distrital de Integración Social - por meio da subdireção para adultez (adultos); o grupo de estudos da Faculdade de Psicologia da Universidad Católica de Colombia - responsável por um trabalho de cartografia social com os habitantes de calle da cidade; a Fundación Pocalana - Organização Não-Governamental $(\mathrm{ONG})$ que realiza todos os sábados à noite a distribuição de alimentos em pontos de alta concentração de habitantes de calle em Bogotá; e a comunidade Donum Christi-Servidores del Servidor Di Padre Pio - comunidade apostólica de laicos que presta auxílio a moradores de rua. Já em Belo Horizonte destacamos a Pastoral de Rua da Arquidiocese de Belo Horizonte - que realiza trabalhos na própria rua e em sua
} 
que têm seus trabalhos e atividades relacionadas às pessoas que moram nas ruas e, posteriormente, o desenvolvimento de ações junto às pessoas moradoras de rua. As ações ocorreram tanto nos equipamentos e sedes relacionados a tais instituições e grupos de assistência quanto nos espaços públicos das duas cidades. Ainda, a partir do caminhar, foram realizadas errâncias e derivas que serviram como forma de experimentar as cidades, o que propiciou o olhar desde longe, a mirada que aos poucos se aproximava, a observação com mais acuidade, a experimentação de distintos destinos, ritmos e velocidades. Finalmente, durante o tempo da pesquisa foram acompanhadas, no âmbito das políticas públicas, atividades das prefeituras locais que evidenciaram debates sobre a questão do morar na rua.

No que concerne os procedimentos genealógicos - aporte metodológico central deste trabalho -, antes de explicitá-los, é necessário discorrer sobre a própria genealogia em Foucault (1999). Para o autor, a genealogia busca "a memória bruta dos combates [...]; o acoplamento dos conhecimentos eruditos e das memórias locais, acoplamento que permite a constituição de um saber histórico das lutas e a utilização desse saber nas táticas atuais" (Foucault, 1999, p. 13). Ou seja, busca compreender os saberes, suas existências e transformações a partir das relações de poder, o que implica numa oposição à pesquisa pela busca da origem ou por desdobramentos meta-históricos e teleológicos. Não é nem a história das teorias, nem a história das ideologias, mas a história daquilo considerado como problema (Entrevista..., 1981). É uma conjugação entre história e corpo. Corpo como superfície de inscrição dos acontecimentos: "A genealogia [...] está portanto no ponto de articulação do corpo com a história. Ela deve mostrar o corpo inteiramente marcado de história e a história arruinando o corpo" (Foucault, 1979, p. 22).

A genealogia analisa as formas de exercício de poder através dos embates do saber em termos de estratégias e táticas de poder, por meio da história das práticas. Como ressaltou Foucault, em uma entrevista concedida no ano de 1981, a história que faz parte da genealogia é a história que fala da nossa atualidade (Entrevista..., 1981). Nela, o saber está situado no âmbito das lutas. E utilizá-la, seria, portanto, uma forma de desassujeitar os saberes históricos, de opô-los à coerção de um discurso teórico, unitário, formal e científico.

Para o exercício maior que foi a tese de doutorado, a genealogia conduziu ao entendimento da história e das ações vinculadas ao planejamento urbano

sede; a Secretaria Municipal Adjunta de Assistência Social (Smaas) - responsável pela gestão da política de assistência social no município de Belo Horizonte; e o Grupo Fraterno de Apoio ao Próximo (GFAP), responsável pela Campanha do Pãozinho que, nas noites de sexta-feira, distribui alimentos para moradores de rua da cidade. 
de Bogotá e de Belo Horizonte, desde o momento de suas fundações até a contemporaneidade. ${ }^{7}$ Esses momentos serviram como base para a empreitada genealógica, mas não com o intuito de reforçar a história oficial de uma cidade, mas, por intermédio dela, de buscar compreender a história das lutas, a batalha constante entre poderes/saberes. Entretanto, para este artigo, na impossibilidade de percorrer cada um desses momentos, focaremos no período que se iniciou com a década de 1990 - no qual estratégias de cunho neoliberal passaram a interferir, cada vez com mais intensidade, na produção do espaço urbano - e que se estende até a contemporaneidade. Desse modo, a partir do levantamento de planos, legislações, normas e projetos de renovação e requalificação urbanos nas duas cidades, buscaremos compreender como se formataram estratégias de assujeitamento das pessoas moradoras de rua. Cabe também destacar que nos ateremos aos mecanismos de poderes/saberes relacionados às políticas urbanas, muito embora, nas duas cidades analisadas, os levantamentos realizados para a tese contemplaram também os arcabouços institucionais e jurídicos no âmbito das políticas sociais.

\section{Moradores de rua e projetos de intervenção e requalificação urbanas: tão perigosos quanto úteis}

Os desdobramentos teórico-metodológicos possibilitaram, no escopo do recorte proposto para este artigo, elucidar relações entre a expansão da implementação de projetos urbanos de cunho neoliberal e formas de assujeitamento às pessoas moradoras de rua. Tanto em Bogotá como em Belo Horizonte, uma nova prática de governo - que é o neoliberalismo -, aprofundou-se a partir da década de 1990 (Montoya, 2012; Paula e Monte-Mór, 2001) e provocou a alteração do papel do estado que passou a criar condições para a expansão do mercado em áreas de provisão social. A terra, a água, a educação, etc., foram paulatinamente transformadas em ativos empresariais, através de sucessivas privatizações. Como consequência, a terra urbana vem

\footnotetext{
${ }^{7}$ Em Bogotá, com base em Mario Perilla (2008), foram quatro os momentos identificados: o da colônia - a partir de sua fundação até a independência; o período iniciado pela independência até princípios do século 20 - marcado pela consolidação de um novo sistema de governo e de grandes transformações na vida de seus habitantes; a irrupção da modernidade - que vai da década de 1930 até o final da década de 1970; e, finalmente, a contemporaneidade, que trouxe novas formas de gestão das cidades e de sua imagem. Em Belo Horizonte, os momentos foram identificados a partir de Paula e Monte-Mór (2004): de 1897 a 1950 - período marcado por uma forte presença do estado na construção da capital, seguida de uma reestruturação que se inicia ao final dos 1940 e permanece até os 1950; dos anos 1950 aos 1980 - assinalado pela consolidação da cidade como polo econômico dinâmico; e, finalmente, de 1980 à atualidade caracterizado por um conjunto de crises que trouxe implicações para a sociedade em termos de emprego, renda, empobrecimento e precarização da infraestrutura.
} 
se tornando um agente econômico por meio de uma nova forma de gestão de seus espaços, o empreendedorismo urbano, que tem atuado, principalmente, através de parcerias público-privadas (Harvey, 2011).

Sob uma perspectiva foucaultina, a prática neoliberal está vinculada à lógica de uma nova governamentalidade, ou seja, a um novo conjunto de relações de poderes/saberes e de técnicas que permitem o exercício de tais relações com vistas a "conduzir a conduta dos outros" (Foucault, 2008b). Essa governamentalidade é, portanto, uma nova arte de governar a humanidade, através de uma prática política calculada, na qual a legitimidade do estado é fundada a partir de um espaço de liberdade dos parceiros econômicos. $\mathrm{O}$ mercado é aquilo que se precisa produzir no governo, pela arte de governar.

Nesse sentido, por meio dos levantamentos realizados, o que pudemos observar nas duas cidades foi que os reflexos dessas alterações ocorreram sob a forma de novos arcabouços institucionais e jurídicos, no âmbito do planejamento e das políticas urbanas, por meio de planos, leis, normas e processos de renovação que incidiram sobre o espaço e, consequentemente, sobre os corpos das pessoas moradoras de rua. O mote dessas ações esteve vinculado a discursos de disciplina, segurança e competitividade. Como consequência, os moradores de rua têm sido vistos como parte das razões da existência de espaços de uma cidade não competitiva e, portanto, compreendidos como corpos anormais e perigosos.

De modo específico, Bogotá, a partir de 1990, no âmbito das políticas de planejamento urbano, foi alvo de sucessivos planos de desenvolvimento e da criação de planos de renovação urbana e de ordenamento territorial. A partir desse período, foram também estabelecidas normas para urbanização que geraram todo um arcabouço que fez com que o estado produzisse um novo mercado para a atuação de empresas. $\mathrm{O}$ marco legal deste processo foi a Constituição de 1991 que respondeu ao novo contexto neoliberal de governança por meio da instauração de uma nova ordem política e de uma ideia de sociedade civil marcada pelas relações público-privadas. A partir de então e, principalmente, após o Plan de ordenamiento territorial regulamentado, em 2000, empresas de renovação urbana passaram a assumir o controle da urbanização e da produção dos espaços da cidade de Bogotá. As parcerias público-privadas, sob esse prisma, tornaram-se um novo mercado de/para ações no território.

É por isso que, para Montoya (2012), o planejamento da cidade ficou reduzido a um conjunto de procedimentos de regulação de relações entre proprietários, produtores e comerciantes do espaço urbano e o estado. $\mathrm{O}$ jurídico-econômico se sobrepôs à concepção urbanística. Por um lado, 
compatibilizaram-se o lucro capitalista e a renovação da cidade. Por outro lado, esse processo urbano ocorreu a partir da produção das desigualdades como forma de acirrar a competitividade. As formas de distribuição de recursos e infraestrutura, por exemplo, não ocorreram de modo a produzir lugares, setores ou áreas de forma igualitária. Ao contrário, o que ocorreu foi a condução e o controle desses processos pelas elites que atuaram de modo a obter benefícios exclusivos por meio da remoção de famílias e populações de baixo ingresso das posições centrais da cidade (Montoya, 2012).

Neste sentido, multiplicaram-se projetos de renovação urbana no centro de Bogotá. Dentre eles destacam-se as requalificações da Plaza de San Victorino (2000), do Eje Ambiental (2001), da Plaza España (2005), do Parque Tercers Milenio (1998); e também projetos ainda não implementados como a Estación de la Sabana; o Plan de renovación urbana Estación Central; o Poyecto de renovación de la Manzana 5; o Plan de renovación parcial Triángulo de Fenicia; o Proyecto Ministerios.

A importância de ressaltar essa área central como lugar de implementação massiva de propostas e projetos de renovação urbana, reside no fato de que o centro desta cidade é o local com maior permanência e circulação de pessoas moradoras de rua. Isso pôde não apenas ser observado durante todo o tempo de pesquisa, como notado em conversas com moradores de rua e pessoas vinculadas ao poder público local:

a população moradora de rua se concentra bastante no centro - Santa Fé, Candelária e Los Mártires - porque é um centro de negócios com toda a parte comercial, turística e histórica que possui [...]. Mártires é uma das localidades que mais possui monumentos históricos [...]. Mas pouco a pouco foram se deteriorando. $O$ governo foi descuidando desta zona que era uma das mais elegantes. As pessoas que tinham mais dinheiro viviam aqui, mas depois foram se deslocando para o norte. Eé onde mais localizam-se moradores de rua porque facilmente encontram material para comercializar, as ollas estão nestes setores e o comércio também. As pessoas que vêm comprar aqui-porque se consegue de tudo com um bom preço - Ihes dão comida, lhes dão roupa. Então, eles não se preocupam com nada. Porque estas mesmas pessoas os mantêm, o comércio os mantém, o trabalho está próximo, a diversão está muito próxima. Por isso, então, o centro é onde eles convivem. Mas não é que não haja moradores de rua em outras localidades da cidade, mas aqui é onde eles se concentram (Representante da Unidade administrativa especial de serviços públicos, informação verbal). ${ }^{8}$

\footnotetext{
${ }^{8}$ Entrevista gravada, em Bogotá, no dia $1^{\circ}$ de dezembro de 2014, no Centro de Peaje de Los Mártires.
} 
De modo semelhante, e seguindo praticamente a mesma temporalidade de bogotana, Belo Horizonte aprovou, em 1996, seu novo plano diretor - que foi revisado nos anos 2000 e 2010. O plano estabeleceu diretrizes específicas para a área central, delimitada pela avenida do Contorno, e para uma zona específica dentro desta, o Hipercentro. Essas regiões tornaram-se locais preferenciais de investimento público, de instalação de equipamentos para serviços públicos e de realização de eventos culturais, de lazer e de turismo.

Neste sentido, o plano e suas revisões criaram formas de articular, promover e conduzir as intervenções urbanas no centro e no Hipercentro da cidade. Para tal, foram instituídos dois procedimentos de grande importância: as Operações Urbanas - "um conjunto integrado de intervenções, com prazo determinado, coordenadas pelo executivo, com a participação de entidades da iniciativa privada, objetivando viabilizar projetos urbanísticos especiais em áreas previamente delimitadas" (Belo Horizonte, 1996) - e os programas de revitalização urbana.

Principalmente no que diz respeito às operações urbanas, sua criação possibilitou a entrada da iniciativa privada de modo mais sistemático na produção do espaço belorizontino. Institucionalizou, na verdade, a entrada do mercado, não mais apenas como agente especulativo alicerçado na mais valia do solo urbano, mas no planejamento e desenho da cidade. Ou seja, o espaço da cidade como um todo, incluindo seus espaços públicos, passou a ser assunto e tema de negociação entre poder público e agentes do capital, principalmente imobiliário.

Quanto aos programas de revitalização urbana, também passíveis de serem desenvolvidos com recursos privados, eles foram definidos como um instrumento de planejamento urbano com vistas a conferir nova qualificação para áreas urbanas específicas e sua reinserção no contexto urbano. Foi nesse contexto que, em 2004, entrou em curso o Programa de requalificação da área central de Belo Horizonte - Programa Centro Vivo - que, até o momento, promoveu: a requalificação ambiental do entorno do Mercado Central e adjacências; a requalificação da avenida Amazonas (na região do hipercentro próxima ao Mercado Central), da praça Raul Soares, da rua Rio de Janeiro, da Rua dos Caetés e adjacências, da praça da Estação, da região Hospitalar, da rua dos Carijós e da praça 7 de setembro; a adequação viária da rua Mato Grosso; a implementação de shoppings populares; ${ }^{9}$ a criação da estação BHbus Central e recuperação do fundo do canal do ribeirão Arrudas (Cruz et al., 2013).

\footnotetext{
${ }_{9}^{9}$ São eles: Oiapoque, Tupinambás, Xavantes, Caetés, Tocantins e Barro Preto. Cada um dos seis shoppings é administrado pela iniciativa privada, com exceção do Caetés, administrado parcialmente pela prefeitura (Cruz et al., 2013).
} 
Já em 2007, como subproduto do Programa Centro Vivo, foi lançado o Plano de Reabilitação do Hipercentro de Belo Horizonte.

Do mesmo modo como em Bogotá, o centro de Belo Horizonte é também o lugar onde os moradores de rua da cidade, em grande medida, desenvolvem suas atividades e constroem seus modos de vida. É o que evidencia um morador de rua de 42 anos e há 22 anos vivendo na rua:

de 2000 para cá, parece que triplicou os moradores de rua [...] e aí começou a prefeitura reprimir o pessoal da rua. [...] ai depois de um tempo foi fundada a Guarda Municipal, ai foi que a coisa piorou mesmo porque a guarda não respeita morador de rua. Como se não bastasse a sociedade passar pela gente na rua e bagunçar com a gente, ai chegou a guarda também para ajudar a bagunçar (Informação verbal). ${ }^{10}$

Nesse sentido, tendo sido expostas as situações e as argumentações relacionadas à produção do espaço nas áreas centrais dessas duas cidades, cabe-nos perguntar: como é possível passar de uma análise de estratégias econômicas no escopo mais vinculado ao espaço urbano e atingir, dentro desse mesmo espaço, as pessoas moradoras de rua?

Para isso, procuramos observar os discursos construídos e que têm servido de base para justificar a execução de grande parte dos projetos de renovação urbana que ocorreram nesse período nas duas cidades. Como forma de exemplificação, destacamos, incialmente, a fala de um arquiteto da prefeitura de Bogotá sobre uma intervenção proposta do Plan de Renovación no ano de 2014: As pessoas não circulam por temor à sua segurança. Assim que melhorar a segurança e as condições urbanas [...], a cidade recuperará um setor que está localizado estrategicamente. De modo quase complementar ao caso evidenciado acima, a argumentação constante em um relatório técnico de um projeto denominado Circuito de Esportes Radicais, que pretendia requalificar, em 2013, o baixio do viaduto Santa Tereza, reforça o argumento sobre as necessidade de medidas urbanísticas como geradoras de condições de segurança:

O viaduto Santa Tereza encontra-se abandonado, com sujidades causadas pelo tempo e mau uso dos usuários. Atualmente, tornou-se abrigo para os moradores de rua. [...] tal projeto é de interesse da Prefeitura Municipal de Belo Horizonte, representando parte fundamental no processo de melhoria e revitalização dos equipamentos públicos urbanos que atualmente encontram-se degradados e não devidamente apropriados e vivenciados pela população (Belo Horizonte, 2013, s.d.).

\footnotetext{
${ }^{10}$ Entrevista gravada no dia 25 de abril de 2015, na praça Rui Barbosa.
} 
Os excertos destacados - longe de esgotarem a gama de justificativas com igual teor -, confirmam o fato de que os espaços que têm sido alvos de intervenções e requalificações urbanas são recorrentemente descritos como, sórdidos, violentos, com altos índices de criminalidade e portadores de espaços públicos destruídos e degradados. Nesse cenário, os moradores de rua têm aparecido como responsáveis - juntamente com prostitutas, vendedores ambulantes, recicladores, usuários de drogas, etc. - pelo mau uso e pelo seu estado de deterioro físico. Em outras palavras, podemos dizer que certos modos de vida vêm sendo considerados como indícios de desordem urbana e, principalmente, de insegurança. São responsabilizados pelo afastamento da população "de bem" e do que se considera "bons" usos. A diferença que recai sobre esses corpos considerados fora da normalidade, mas que sempre estiveram presentes nessas cidades desde suas fundações é a de que, neste momento, eles não são mais os não europeus, os não letrados, os não trabalhadores, os doentes, ou os feios e sórdidos - como denominados em outros momentos históricos. A população que vive nas ruas, nesse período sobre o qual nos debruçamos, conforma a horda dos inseguros. São os corpos da insegurança e do perigo. Corpos perigosos.

Assim, pode-se verificar, portanto, que a presença dessas pessoas foi, de maneira pragmática, servindo de justificava para sucessivas demolições e requalificações urbanas nas duas cidades estudadas. De acordo com Montoya (2012), tornaram-se, por sua vez, indício da alteração da forma de governar o urbano, ao colocar a segurança como tema central da política pública. $\mathrm{O}$ urbanismo, nesse momento, de acordo com o autor, fez da segurança um componente central da governamentalidade num contexto de globalização.

Assim, a população de moradores de rua é usada para justificar o discurso favorável às intervenções urbanas. Como embasar os megaprojetos de renovação urbana e como justificar a necessidade de "fazer renascer o centro" se essas populações não existissem? Os fenômenos de violência, insegurança e deterioro vinculados, sobremaneira, aos moradores de rua são úteis e imprescindíveis para a ação do mercado especulativo e imobiliário no solo urbano. Em outras palavras, os moradores de rua - representantes da desigualdade e, por isso, incrementadores da concorrência e da privatização do risco; população "perigosa" que justifica a atuação de mecanismos de coerção e controle nos espaços urbanos - têm se tornado peça importante para garantir a expansão do mercado no solo urbano através, principalmente, das novas combinações e alianças entre estado e empresas. Eles não estão aquém ou além desta arte de governo neoliberal. Eles são parte de suas estratégias. Nesse sentido, a governamentalidade neoliberal tem produzido, 
por meio de mecanismos e estratégias disciplinares e biopolítcas, seus sujeitos não-conformes. A cidade-mercado-capital tem se utilizado dos moradores de rua para garantir sua perpetuação, para garantir, sob o aspecto da cidade, a constante renovação do espaço urbano.

É exatamente neste ponto que pudemos observar que os espaços onde, majoritariamente, as pessoas que moram nas ruas se concentram, não foram meramente tomados por essa população, mas foram deixados a se tornarem territórios que têm acolhido populações historicamente já vulnerabilizadas e invisibilizadas pela assimetria na implementação de políticas públicas. Nesse sentido, os conjuntos de ações conduzidas pelos poderes públicos locais têm buscado, menos arcar com as dívidas históricas vinculadas à exploração e à sujeição dos corpos que deles se apropriam e mais como oportunidade para que a elite controladora da produção dos espaços da cidade possa dar continuidade aos processos homegeneizantes de transformação empreendedorista sobre o tecido urbano. A terra urbana degradada e seu entorno podem ser comprados a baixo preço e, após investimentos, a médio e longo prazo, trazem grandes retornos financeiros. Nesse âmbito, os corpos dos moradores de rua, considerados anormais tanto como indivíduos como na dimensão da população, passam a ser compreendidos não mais como um problema para a cidade e seus espaços, mas como uma parte da lógica de destruição criativa do espaço político-econômico que se espraia nos tecidos urbanos das cidades. Tornam-se corpos úteis e tão antigos quanto a história dos próprios centros urbanos. Ou seja, ao mesmo tempo que temporariamente impedem, justificam e renovam as possibilidades de investimentos na lógica neoliberal.

\section{Conclusão}

A governamentalidade neoliberal aprofundou os mecanismos do poder disciplinar e do biopoder e fez da gestão da população e do urbano coisas de mercado. A cidade é mais um insumo do mercado que se alastra. Cidade commodity que, ao organizar a população, organiza a base das "formas empresa". Tanto em Bogotá como em Belo Horizonte, a produção do espaço citadino resultou de mecanismos, estratégias e táticas de poderes/saberes que, num campo de lutas colocaram em exercício os modos de fazer de uma tecnologia política que incide sobre os corpos. Os estudos realizados mostraram que nas áreas de pesquisa e análise, mesmo com os sucessivos planos, projetos, leis, códigos, normativas e regulamentações, essas pessoas que moram nas ruas continuaram, pelos seus modos de vida, a produzir espaços. E, ao [r] existirem, têm justificado o discurso favorável às intervenções urbanas. 


\section{Referências}

BELO Horizonte. Lei n. 6.165, de 27 de agosto de 1996. Institui o Plano Diretor do município de Belo Horizonte. Câmara Municipal de Belo Horizonte. Belo Horizonte, 27 de agosto de 1996.

BELO Horizonte. Relatório técnico. Circuito de Esportes Radicais Santa Tereza. Belo Horizonte: PMBH/Smobi, 2013.

CORTÉS, José Miguel. Politicas do espaço: arquitetura, gênero e controle social. São Paulo: Editora Senac, 2008.

CRUZ, Luana; FIGUEIRAS, Paulo; SILVA, Cristiane. PBH abre licitação para projetos de revitalização de espaços sob viadutos. Estado de Minas. Belo Horizonte, 24 out. $2013<$ em.com.br/app/noticia/gerais/2013/10/24/interna_gerais,463386/pbhabre-licitacao-para-projetos-de-revitalizacao-de-espacos-sob-viadutos.shtml> (24 dez. 2018).

DELEUZE, Gilles. Cours Vincennes, 24/01/1978<webdeleuze.com/textes/194>.

DUARTE, André de Macedo. Foucault e as novas figuras da biopolitica: o fascismo contemporâneo, $2009<$ works.bepress.com/andre_duarte/19>.

ELDEN, Stuart. Mapping the present-Heidegger, Foucault and the project of a spatial history. London: Continuum Publishing, 2001.

ENTREVISTA com Michel Foucault. Lovain, $1981<$ youtube.com/watch?v=0H2gqp JTu4E\&feature $=$ youtu.be $>$.

FAVRET-SAADA, Jeanne. Ser afetado. Cadernos de campo, v. 13, n. 13, p. 155-161, 2005.

FOUCAULT, Michel. O nascimento da clínica. Rio de Janeiro: Forense Universitária, 1977.

FOUCAULT, Michel. A história da loucura na idade clássica. São Paulo: Perspectiva, 1978.

FOUCAULT, Michel. Microfisica do poder. Rio de Janeiro: Edições Graal, 1979.

FOUCAULT, Michel. História da sexualidade I: a vontade de saber. Rio de Janeiro: Edições Graal, 1988.

FOUCAULT, Michel. Em defesa da sociedade: curso dado no Collège de France (1975-1976). São Paulo: Martins Fontes, 1999.

FOUCAULT, Michel. Segurança, território, população: curso dado no Collège de France (1977-1978). São Paulo: Martins Fontes, 2008a.

FOUCAULT, Michel. O nascimento da biopolítica: curso dado no Collège de France (1978-1979). São Paulo: Martins Fontes, 2008b.

FOUCAULT, Michel. Vigiar e punir: nascimento da prisão. Petrópolis: Vozes, 2009.

HARVEY, David. O neoliberalismo: história e implicações. São Paulo: Edições Loyola, 2011.

MONTOYA. John Williams. Bogotá: crecimiento urbano e cambio morofológico, 1538-2010. Quebéc: Université Laval, 2012. Tese doutorado. 
NASCIMENTO, Cristiano. O edifício como espaço analítico. Arquitextos: vitruvius. v. 8, $2008<$ vitruvius.es/revistas/read/arquitextos/08.093/168>.

PAULA, José Antônio; MONTE-MÓR, Roberto Luís. Formação histórica: três momentos da história de Belo Horizonte. Belo Horizonte: Universidade Federal de Minas Gerais, 2004.

PERILLA, Mario. El habitar en la Jiménez con Séptima de Bogotá: historia, memoria, cuerpo. Bogotá: Universidad Nacional de Colombia, 2008.

PRIGGE, Walter. Reading the urban revolution. In: Kanishka Goonewardena; Stefan Kipfer; Richard Milgrom; Christian Schmid. Space, difference, everyday life: reading Henri Lefebvre. New York: Taylor \& Francis, 2008. p. 46-61.

SANTOS, Carlos Nelson Ferreira dos. A cidade como um jogo de cartas. Niterói: EdUFF; São Paulo: Projeto Editores, 1988.

Recebido: 30 maio 2018

Aceito: 20 nov. 2018

Publicado: 01 mar. 2019

Endereço da autora:

Karine Gonçalves Carneiro

Universidade Federal de Ouro Preto

Departamento de Arquitetura e Urbanismo

Campus Morro Cruzeiro - Bauxita

35400-000 Ouro Preto, MG, Brasil

KARINE GONÇALVES CARNEIRO < carneirokari@gmail.com>

Doutora em Ciências Sociais (Puc-Minas, Belo Horizonte, Brasil) com estágio doutoral no departamento de Sociologia da Universidad Nacional de Colombia (Bogotá, Colômbia). Professora adjunta do departamento de Arquitetura e Urbanismo da Universidade Federal de Ouro Preto (Ouro Preto, MG, Brasil).

Orcid: https://orcid.org/0000-0002-0786-8465 